\title{
Adoption of the American Academy of Pediatrics' neonatal hyperbilirubinemia guidelines and its effect on blood exchange transfusion rate in a tertiary care center in Amman, Jordan
}

This article was published in the following Dove Press journal:

Journal of Blood Medicine

\section{Manar Al-Lawama \\ Eman Al-Rimawi \\ Rawan Al-Shibi \\ Eman Badran}

Department of Pediatrics, The University of Jordan, School of Medicine, Amman, Jordan
Correspondence: Manar Al-Lawama The University of Jordan, Jordan University Hospital, Queen Rania Street, I 1943 Amman, Jordan

Tel +962799068565

Email Manar-76@hotmail.com
Introduction: Severe neonatal hyperbilirubinemia can cause mortality and serious morbidities. When phototherapy fails, neonates with severe hyperbilirubinemia should undergo double volume blood exchange transfusion (BET). As this procedure carries a significant risk of mortality and morbidity, adopting guidelines for the treatment of neonatal hyperbilirubinemia is critical to avoid hyperbilirubinemia toxicity and also the complication of an unindicated procedure.

Methods: This study investigated the causes, complications, and trend of BET rate in our unit over a 13-year period. The medical charts and laboratory databases of all infants who underwent BET in Jordan University Hospital between 2003 and 2015 were retrospectively reviewed.

Results: The rate of exchange cases decreased significantly after adopting the guidelines of American Academy of Pediatrics $(P<0.0001)$. Most neonates were term newborns $(69 \%)$. Average birth weight was $2,800 \mathrm{~g}$. The most common causes of exchange transfusion were non-hemolytic conditions. Late prematurity alone accounted for $20 \%$ of the cases. Thrombocytopenia was the most commonly encountered complication (33\%). Chronic neurological complications were seen in $12 \%$ of those who were followed for $>12$ months of age.

Conclusions: This study showed a clear decline in the rate of BET after implementing the guidelines of American Academy of Pediatrics. In addition to improving the strategies for the identification and follow-up of at-risk newborns, we should intensify our efforts to prevent the progression of neonatal hyperbilirubinemia to the exchange level by enhancing parents' awareness of this potentially harmful neonatal condition.

Keywords: neonate, exchange transfusion, hyperbilirubinemia, guidelines, Jordan

\section{Introduction}

Neonatal hyperbilirubinemia is a common phenomenon that is usually benign. ${ }^{1}$ However, severe neonatal hyperbilirubinemia can cause mortality and serious morbidities. ${ }^{2}$ When neonates with severe hyperbilirubinemia fail to respond to phototherapy, double volume blood exchange transfusion (BET) is the only option. ${ }^{3}$ As this procedure carries a significant rate of complications, ${ }^{4}$ neonatal hyperbilirubinemia guidelines are critical to avoid both hyperbilirubinemia toxicity and the complication of an invasive therapy. 3.5

The present study was conducted to investigate the rate of BET and its complications. Furthermore, the effect of adopting the guidelines outlined by the American Academy of Pediatrics (AAP) ${ }^{3}$ on the rate of BET in our institution was also investigated. 


\section{Patients and methods}

This study examined neonatal exchange transfusion due to indirect hyperbilirubinemia. We aimed to study the causes, complications, and trend of the exchange transfusion rate in our unit over a 13-year period. The medical charts and laboratory databases of all infants who underwent BET in Jordan University Hospital between 2003 and 2015 were retrospectively reviewed. The study was approved by the Deanship of Scientific Research at the University of Jordan and was reviewed and approved by the Institutional Review Board Committee and the Ethical Committee at the University of Jordan. Patient's consent to review medical charts was not required due to the retrospective nature of the study which does not include patient identifiers. To insure patient's confidentiality, medical charts revision process is only allowed inside the medical charts department. All the authors in this study had the privilege to access files of pediatric patients in Jordan University Hospital.

\section{Setting}

Our university hospital is a tertiary center, with $>4,000$ deliveries/year. The neonatal unit provides care for premature infants and sick neonates, with a capacity of 30 beds. The hospital delivers post-discharge well-newborn services, including physical examination and neonatal screen within 72 hours of discharge.

\section{Antenatal screening and management}

All pregnant women followed in Jordan University Hospital have their blood tested for $\mathrm{ABO}$ grouping and $\mathrm{RhD}$ typing and for antibodies using the indirect antiglobulin test (IAT). Anti-D immunoglobulins are administered to Rh-negative women antenatally and postnatally accordingly. In case of sensitization, follow-up is performed by serial IAT titers and by monitoring the development of anemia in the infants using the middle cerebral artery Doppler measurement. Intrauterine blood transfusion is performed for severely anemic fetuses.

\section{Neonatal screening protocol}

Jordan University Hospital guidelines indicate that all neonates born to $\mathrm{Rh}$-negative mothers, blood group type $\mathrm{O}$ mothers, positive IAT mothers, or to mothers with unknown blood group are screened by the direct antiglobulin test (DAT) and have their bilirubin level measured using cord blood. Cord blood DAT results were considered reliable and were not confirmed by peripheral blood samples. Any newborn whose DAT was positive or cord bilirubin level was $\geq 3 \mathrm{mg} /$ dL immediately had their serum bilirubin level measured, and then serial measurements were performed every 4-6 hours, depending on the degree of rise. All other newborns had their serum bilirubin level measured whenever they developed jaundice.

Two years ago, regardless of their clinical jaundice status, we began screening all newborns prior to discharge using a transcutaneous bilirubinometer. Data from these 2 years have not been included in the current study.

\section{Phototherapy}

Phototherapy is initiated when newborns' serum bilirubin reaches phototherapy level. Phototherapy level is affected by the newborn's age, presence of risk factors that increase bilirubin toxicity such as hemolysis, glucose-6-phosphate dehydrogenase (G6PD) enzyme deficiency, sepsis, etc. ${ }^{6}$ Prophylactic phototherapy is not routinely practiced in our unit. An intensive phototherapy $360^{\circ}$ cradle was introduced to the service in 2009 .

\section{Intravenous immunoglobulin (IVIG) use}

IVIGs are used only when the DAT of the infant is positive and there is evidence of ongoing hemolysis. The attending on-call in our unit refers to 2 protocols for the use of IVIG. This treatment is implemented either according to the AAP guidelines whenever the bilirubin level is $2 \mathrm{mg} / \mathrm{dL}$ below the exchange level in a newborn with hemolytic disease and a positive DAT, or whenever the newborn has a positive DAT and his/her bilirubin level reaches phototherapy level. The rationale of the second approach is that an increasing bilirubin level reaching the threshold of therapy means significant hemolysis. Furthermore, when following the AAP guidelines, the time required for IVIG transfusion might be too long to be of benefit when the rate of rise is rapid and the infant is only $2 \mathrm{mg} / \mathrm{dL}$ away from exchange. The dose of IVIG is $1 \mathrm{~g} /$ $\mathrm{kg}$ over 2 hours. During IVIG transfusion, the newborn infant is placed on continuous cardiorespiratory monitoring. and vital signs are documented every 15 minutes. If any reaction develops, the transfusion is stopped, and the physician is called to evaluate the newborn and administer medication if needed.

\section{Exchange transfusion: threshold}

Exchange transfusion is performed for infants presenting with acute bilirubin encephalopathy or whose bilirubin is at the exchange level and fails to respond to phototherapy. Prior to 2008, a serum bilirubin level of $20 \mathrm{mg} / \mathrm{dL}$ was the exchange level for healthy term infants. ${ }^{7}$ At the end of 2008, the AAP guidelines ${ }^{3}$ for phototherapy and the exchange level were fully adopted. 


\section{Exchange transfusion: preparation}

Once the bilirubin level is at, or approaching, the exchange level, a compatibility cross-matching is done using $\mathrm{O} R \mathrm{RD}$ negative or $\mathrm{ABO}$-compatible $\mathrm{RhD}$-negative packed red blood cells (PRBCs).The transfused blood is filtered as per our blood bank protocol. Blood irradiation is not available in Jordan University Hospital. A volume of $90 \mathrm{cc} / \mathrm{kg}$ is prepared and reconstituted with an equal volume of AB-positive fresh frozen plasma. Reconstitution is performed only when the decision for exchange is taken. The blood should not be $>5$ days old. If only older PRBCs are available, washed PRBCs should be used. Cytomegalovirus-negative blood is only requested when the newborn is premature, $<34$ weeks gestational age. The blood bank in Jordan University Hospital uses calcium citrate as a preservative. Parents are informed of the procedure and its benefits and potential complications.

\section{Exchange transfusion: procedure}

Exchange transfusion is performed using an umbilical venous catheter. A pre-prepared exchange set is employed. The provided data sheet is used for documenting the exchanged volumes of blood and should be kept in the newborn's chart. Blood is exchanged in small aliquots $(5-10 \mathrm{cc})$. During the exchange, the newborn is on continuous cardiorespiratory monitoring. If the newborn becomes bradycardic, the procedure is stopped, and the newborn receives resuscitation according to the neonatal resuscitation guidelines ${ }^{8,9}$ and also receives $200 \mathrm{mg} / \mathrm{kg}$ calcium gluconate intravenously. Feeding is stopped, and intravenous fluid is started upon approaching the exchange level and this continues for 24 hours after the exchange transfusion, provided the bilirubin level is falling. The umbilical venous catheter is retained until 24 hours after the exchange or until the level of bilirubin continuously falls, whichever is later. Antibiotics are not routinely administered unless there is a suspicion of sepsis. Fluids are not routinely increased unless dehydration is present.

\section{Laboratory investigations}

The first $5 \mathrm{cc}$ of blood withdrawn is sent to the laboratory for the following analyses: complete blood count, blood film, electrolytes, calcium, alanine transaminase, G6PD, and thyroid function test. The final $5 \mathrm{cc}$ undergoes the same investigations except for G6PD and thyroid function test.

The bilirubin level is measured every $4-6$ hours depending on the degree of rise, and the $\mathrm{Hb}$ level is measured at least every 12 hours.

\section{Statistical analysis}

Overall trends in exchange transfusion are presented for the period 2003-2015 (before and after adoption of the AAP guidelines) and assessed by $\chi^{2}$ for trend tests. Other data are presented as numbers and frequencies. A $P$-value $<0.05$ is considered statistically significant.

\section{Results}

The rate of exchange cases decreased significantly after adoption of the AAP guidelines at the end of 2008 (Figure 1). There were 20,730 live newborns between 2003 and 2008, with 38 cases of BET. Between 2009 and 2015, there were 35,041 live newborns with 7 cases of BET $(P<0.0001)$. Most

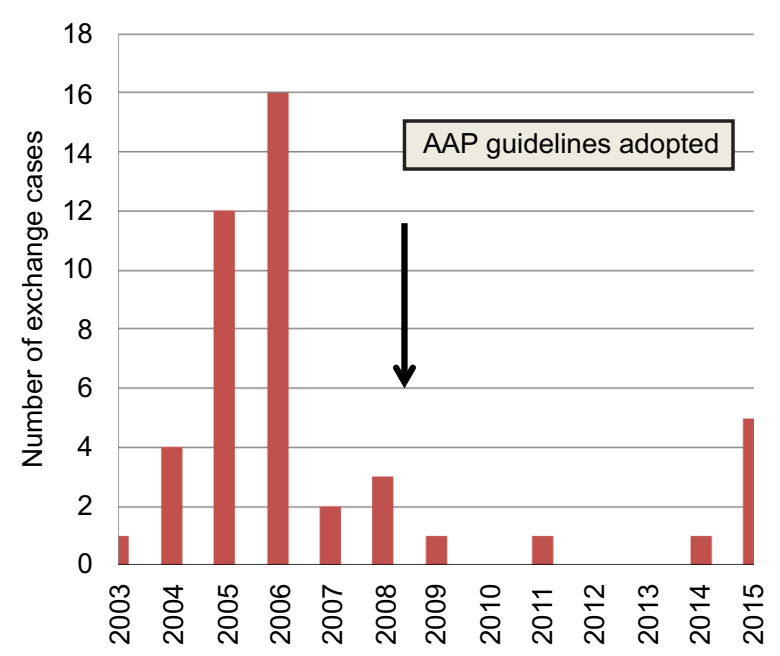

Figure I Number of exchange cases during the study period with the change in rate illustrated before and after the adoption of the AAP hyperbilirubinemia guidelines. Abbreviation: AAP, American Academy of Pediatrics. 
neonates who underwent BET were term newborns (69\%). Their average birth weight was 2,800 g. Most mothers had $\mathrm{O}$ blood group and were $\mathrm{Rh}$ positive. Most newborns were admitted due to hyperbilirubinemia. The demographic data and hospitalization characteristics are detailed in Table 1.

The most common causes of exchange transfusion were non-hemolytic conditions. A $2 \times 2$ contingency table was used to compare the rate of severe hyperbilirubinemia between hemolytic and non-hemolytic cases; there was no significant difference with $P$-value of 0.2 and odds ratio of 0.4 (95\% CI: 0.094-1.68). Late prematurity alone accounted for 9 cases (Table 2). Thrombocytopenia was the most commonly encountered complication (33\%). Chronic neurological complications were seen in $12 \%$ of those who were followed for $>12$ months of age (Table 3 ).

Table I Demographic and hospitalization data of neonates who underwent exchange transfusion in a tertiary care center in Jordan

\begin{tabular}{|c|c|}
\hline Characteristics & Number (\%) \\
\hline \multicolumn{2}{|l|}{ Gestational age } \\
\hline Term $\left(37^{0}-41^{6}\right)$ weeks & $31(69)$ \\
\hline Late preterm $\left(34^{0}-36^{6}\right)$ weeks & $13(29)$ \\
\hline Preterm $<34$ weeks & $I(2)$ \\
\hline Birth weight (average \pm SD), g & $2,800 \pm 745$ \\
\hline Male & $26(58)$ \\
\hline \multicolumn{2}{|l|}{ Mode of delivery } \\
\hline $\mathrm{C} / \mathrm{S}$ & $17(38)$ \\
\hline Vacuum & $3(6)$ \\
\hline SVD & $25(56)$ \\
\hline \multicolumn{2}{|l|}{ Apgar score (average) } \\
\hline At I minute & 7 \\
\hline At 5 minutes & 9 \\
\hline \multicolumn{2}{|l|}{ Maternal blood group } \\
\hline A & $14(31)$ \\
\hline B & $2(4)$ \\
\hline$A B$ & $3(6)$ \\
\hline $\mathrm{O}$ & $24(53)$ \\
\hline Unknown & $2(4)$ \\
\hline \multicolumn{2}{|l|}{ Rh type } \\
\hline Positive & $40(89)$ \\
\hline Negative & $3(7)$ \\
\hline Unknown & $2(4)$ \\
\hline \multicolumn{2}{|l|}{ Siblings' history } \\
\hline Previous sibling needed phototherapy & $5(11)$ \\
\hline Previous sibling needed exchange & $\mathrm{I}(2)$ \\
\hline \multicolumn{2}{|l|}{ Admission's status and hospital course } \\
\hline Admission due to hyperbilirubinemia & $34(76)$ \\
\hline Sever hyperbilirubinemia on admission & $23(5 \mathrm{I})$ \\
\hline Highest bilirubin $>20 \mathrm{mg} / \mathrm{dL}$ at any time & $35(78)$ \\
\hline Received phototherapy & $45(100)$ \\
\hline Received IVIG & II (24) \\
\hline Rate of bilirubin decrease post exchange (average $\pm S D$ ) & $61 \pm 9$ \\
\hline
\end{tabular}

Abbreviations: C/S, Cesarean section; IVIG, intravenous immunoglobulin; SVD, spontaneous vaginal delivery.
Table 2 Causes of exchange transfusion in tertiary health care center in Jordan over a 13-year period

\begin{tabular}{ll}
\hline Cause & Number \\
\hline Hemolytic (15) & \\
Rh isoimmunization & $\mathrm{I}$ \\
ABO incompatibility & 8 \\
Minor blood group & 3 \\
Rh with IUT & $\mathrm{I}$ \\
G6PD enzyme deficiency & 2 \\
Non-hemolytic (26) & \\
Sepsis & 6 \\
Premature & $\mathrm{I}$ \\
Late premature & 9 \\
Dehydration & 2 \\
Hypothyroidism & $\mathrm{I}$ \\
Breast milk & 2 \\
Exaggerated physiologic & $\mathrm{I}$ \\
Cephalohematoma & $\mathrm{I}$ \\
LGA & 2 \\
Crigler-Najjar & $\mathrm{I}$ \\
Unknown (4) & \\
\hline
\end{tabular}

Abbreviations: G6PD, glucose-6-phosphate dehydrogenase; IUT, intra-uterine transfusion; LGA, large for gestational age.

Table 3 Short- and long-term complications of neonates who underwent exchange transfusion in tertiary care center in Jordan

\begin{tabular}{|c|c|}
\hline Outcome & Number (\%) \\
\hline \multicolumn{2}{|l|}{ Cardiovascular } \\
\hline Bradycardia (mild) ${ }^{\mathrm{a}}$ & I (2) \\
\hline Bradycardia needing CPR ${ }^{a}$ & I (2) \\
\hline Limb cyanosis $^{a}$ & I (2) \\
\hline \multicolumn{2}{|l|}{ Metabolic } \\
\hline Hypomagnesemia ${ }^{\mathrm{b}}$ & $2(4)$ \\
\hline Hyperglycemia $^{\mathrm{b}}$ & $7(16)$ \\
\hline \multicolumn{2}{|l|}{ Hematologic } \\
\hline Thrombocytopenia $^{\mathrm{b}}$ & $15(33)$ \\
\hline Platelet transfusion ${ }^{b}$ & $3(7)$ \\
\hline Anemia $^{c}$ & II (24) \\
\hline PRBCs transfusion ${ }^{c}$ & $4(9)$ \\
\hline \multicolumn{2}{|l|}{ Hepatic } \\
\hline Cholestasis & I (2) \\
\hline \multicolumn{2}{|l|}{ Follow-up and neurological complications } \\
\hline Post-discharge visit for at least I time & $35(78)$ \\
\hline Post-discharge follow-up for more than I year of age & $25(56)$ \\
\hline Developmental delay and seizures & $2(8)$ \\
\hline Spasticity & I (4) \\
\hline Hearing deficit & I (4) \\
\hline
\end{tabular}

Note: a During exchange, ${ }^{b}$ post exchange, and cany time before discharge.

Abbreviations: CPR, cardiopulmonary resuscitation; PRBCs, packed red blood cells.

\section{Discussion}

Exchange transfusion for neonatal hyperbilirubinemia is an effective procedure for preventing chronic bilirubin encephalopathy. ${ }^{10}$ However; it carries a significant risk of mortality and morbidity. ${ }^{11}$ 
The rate of BET is declining worldwide. ${ }^{12,13}$ Many factors have contributed to this, mainly antenatal antibody screening, anti-D administration, ${ }^{14,15}$ intensive phototherapy, ${ }^{16}$ and the use of IVIG. ${ }^{17}$ The adoption of neonatal screening programs and the change in therapeutic thresholds have also contributed greatly to the improvement of neonatal severe hyperbilirubinemia outcomes and the decline in the BET rate. ${ }^{3,11}$

In this study, we investigated the trend of neonatal BET in our unit over a 13-year period, focusing on the stage of complete adoption of the AAP guidelines for the treatment of severe neonatal hyperbilirubinemia. A decrease in the rate of BET after adoption of the AAP guidelines has previously been reported. ${ }^{5,18}$ This finding was also clearly demonstrated in our cohort (Figure 1). The AAP guidelines offered more structured approach to neonates approaching exchange level. The time of making the decision to perform exchange was a major change. The decision is based on the response to phototherapy and whether the treatment is successful in decreasing the bilirubin below exchange level, rather than the initial bilirubin prior to starting phototherapy. ${ }^{3}$ Other major revisions that the AAP guidelines introduced into our practice were the change in the exchange level for healthy term newborns (which used to be $20 \mathrm{mg} / \mathrm{dL}$ ) and IVIG administration for DAT-positive hemolytic diseases. The AAP guidelines were introduced earlier to our unit but were not adopted fully by all treating physicians; this might explain the earlier decline of exchange transfusion cases starting prior to the significant decline that happened in 2008.

During the time of AAP guidelines adoption, we also introduced a $360^{\circ}$ phototherapy cradle unit. It is highly likely that this improved the rate of phototherapy response in infants with severe hyperbilirubinemia and played a role in the BET rate decline. ${ }^{19,20}$

In contrast to previous studies, hemolytic conditions were not the most common cause of severe hyperbilirubinemia that led to BET in our cohort. ${ }^{12,13}$ This might reflect the strict approach our institution applies during antenatal care to identify and follow-up at-risk newborns. All neonates with a positive DAT are identified pre-discharge and go home with a plan for bilirubin follow-up. Intensive phototherapy and IVIG treatment almost certainly contributed to the better outcomes in hemolytic situations.

The predisposition of late premature infants to severe hyperbilirubinemia has been previously documented. ${ }^{21}$ In this study, there were 9 patients who did not have any identified cause of their severe hyperbilirubinemia except for being late premature newborns. This highlights the importance of close follow-up of late preterm newborns without apparent risk factors for severe hyperbilirubinemia.

Several side effects of BET have previously been reported, primarily thrombocytopenia and metabolic disturbances. ${ }^{13}$ In our cohort, thrombocytopenia was the most commonly encountered short-term complication. None of the newborn infants had thrombocytopenia prior to exchange. Immune-mediated reactions due to the presence of platelet $\mathrm{A}$ immunoglobulin $\mathrm{G}$ in donor plasma may explain the severe thrombocytopenia cases that required platelet transfusions, ${ }^{22}$ whereas dilution effects of transfused blood might explain the milder cases. There was no hemorrhagic complication encountered.

Outpatient clinic follow-up for $>1$ year of age was achieved in only $56 \%$ of the patients. Chronic neurological deficits were found in $3(12 \%)$ of those patients. All were male newborns and had normal G6PD levels. The first patient was a late preterm newborn and had a bilirubin level of $40 \mathrm{mg} / \mathrm{dL}$. The second patient was a small-for-gestational age late preterm newborn and had a bilirubin level of $15 \mathrm{mg} / \mathrm{dL}$. Their hyperbilirubinemia cause was not identified. The third patient had hemolysis due to $\mathrm{Rh}$ isoimmunization and his highest bilirubin level was 34 $\mathrm{mg} / \mathrm{dL}$, and he received IVIG. In addition to sever hyperbilirubinemia, the first 2 infants were at higher risk for adverse neurodevelopment outcomes due to their gestational age. ${ }^{23}$

This study showed a clear decline in the rate of BET after implementation of the AAP guidelines. In addition to improving the identification and follow-up strategies of atrisk newborns, we should intensify our efforts to prevent the progression of neonatal hyperbilirubinemia to the exchange level by enhancing parents' awareness of this potentially harmful neonatal condition, which was recently shown to be lacking in our population. ${ }^{24}$

\section{Disclosure}

The authors report no conflicts of interest in this work.

\section{References}

1. Bhutani VK, Stark AR, Lazzeroni LC, et al; Initial Clinical Testing Evaluation and Risk Assessment for Universal Screening for Hyperbilirubinemia Study Group. Predischarge screening for severe neonatal hyperbilirubinemia identifies infants who need phototherapy. J Pediatr. 2013;162(3):477.e1-482.e1.

2. Sgro M, Campbell D, Shah V. Incidence and causes of severe neonatal hyperbilirubinemia in Canada. CMAJ. 2006;175(6):587-590.

3. American Academy of Pediatrics Subcommittee on Hyperbilirubinemia Management of hyperbilirubinemia in the newborn infant 35 or more weeks of gestation. Pediatrics. 2004;114(1):297-316.

4. Abu-Ekteish F, Daoud A, Rimawi H, Kakish K, Abu-Heija A. Neonatal exchange transfusion: a Jordanian experience. Ann Trop Paediatr. 2000;20(1):57-60. 
5. Jangaard KA, Allen A. Changes in practice patterns for treatment of hyperbilirubinemia in healthy, full term infants in Nova Scotia, Canada following the AAP practice parameters. Paediatr Child Health. 2002; 7(Suppl A):22A-23A.

6. Bhutani VK, Johnson L, Sivieri EM. Predictive ability of a predischarge hour-specific serum bilirubin for subsequent significant hyperbilirubinemia in healthy term and near-term newborns. Pediatrics. 1999;103(1):6-14.

7. Maisels MJ, Newman TB. Kernicterus in otherwise healthy, breast-fed term newborns. Pediatrics. 1995;96(4 Pt 1):730-733.

8. Wyckoff MH, Aziz K, Escobedo MB, et al. Part 13: Neonatal Resuscitation: 2015 American Heart Association Guidelines Update for Cardiopulmonary Resuscitation and Emergency Cardiovascular Care. Circulation. 2015;132(18 Suppl 2):S543-S560.

9. NANN Board of Directors. Prevention of acute bilirubin encephalopathy and kernicterus in newborns: position statement \#3049. Adv Neonatal Care. 2011;11(5 Suppl):S3-S9.

10. Olusanya BO, Ogunlesi TA, Slusher TM. Why is kernicterus still a major cause of death and disability in low-income and middle-income countries?. Arch Dis Child. 2014;99(12):1117-1121.

11. Chessman JC, Bowen JR, Ford JB. Neonatal exchange transfusions in tertiary and non-tertiary hospital settings, New South Wales, 2001-2012. J Paediatr Child Health. 2017;53(5):447-450.

12. Hakan N, Zenciroglu A, Aydin M, Okumus N, Dursun A, Dilli D. Exchange transfusion for neonatal hyperbilirubinemia: an 8-year single center experience at a tertiary neonatal intensive care unit in Turkey. $J$ Matern Fetal Neonatal Med. 2014;28(13):1537-1541.

13. Bujandric N, Grujic J. Exchange transfusion for severe neonatal hyperbilirubinemia: 17 years' experience from Vojvodina, Serbia. Indian $J$ Hematol Blood Transfus. 2015;32(2):208-214.

14. Liumbruno GM, D'Alessandro A, Rea F, et al. The role of antenatal immunoprophylaxis in the prevention of maternal-fetal anti-Rh (D) alloimmunisation. Blood Transfus. 2010;8(1):8-16.
15. Harding HL, Martlew VJ, McFadyen IR, Clarke CA. Preventing Rhesus D haemolytic disease of the newborn by giving anti-D immunoglobulin: are the guidelines being adequately followed?. Br J Obstet Gynaecol. 1997;104(1):869-870.

16. Edris AA, Ghany EA, Razek AR, Zahran AM. The role of intensive phototherapy in decreasing the need for exchange transfusion in neonatal jaundice. J Pak Med Assoc. 2014;64(1):5-8.

17. Cortey A, Elzaabi M, Waegemans T, Roch B, Aujard Y. [Efficacy and safety of intravenous immunoglobulins in the management of neonatal hyperbilirubinemia due to ABO incompatibility: a meta-analysis]. Arch Pediatr. 2014;21(9):976-983. French.

18. Steiner LA, Bizzarro MJ, Ehrenkranz RA, Gallagher PG. A decline in the frequency of neonatal exchange transfusions and its effect on exchangerelated morbidity and mortality. Pediatrics. 2007;120(1):27-32.

19. Abd-Ellatif MA, Abd-Ellatif DA. The use of intensive phototherapy in severe neonatal hyperbilirubinemia. J Egypt Soc Parasitol. 2012; 42(2):483-493.

20. de Carvalho M, Mochdece CC, Sá CA, Moreira ME. High-intensity phototherapy for the treatment of severe non haemolytic neonatal hyperbilirubinemia. Acta Paediatr. 2011;100(4):620-623.

21. Reichman NE, Teitler JO, Moullin S, Ostfeld BM, Hegyi T. Late-preterm birth and neonatal morbidities: population-level and within-family estimates. Ann Epidemiol. 2015;25(2):126-132.

22. Forster J, Schmidt B, Künzer W. [Use of an immunoenzyme microtechnic for quantitative determination of platelet-associated IgG in pediatrics. Acute idiopathic thrombocytopenia purpura and thrombocytopenia following exchange transfusion]. Monatsschr Kinderheilkd. 1983;131(3):157-160.

23. Vohr B. Long-term outcomes of moderately preterm, late preterm, and early term infants. Clin Perinatol. 2013;40(4):739-751.

24. Al-lawama M, Albaramki J, Karajeh D, Dmour H. Maternal knowledge of neonatal jaundice and its relation to their level of education in Amman, Jordan. Kasmera. 2017;45(1):1-18.
Journal of Blood Medicine

\section{Publish your work in this journal}

The Journal of Blood Medicine is an international, peer-reviewed, open access, online journal publishing laboratory, experimental and clinical aspects of all aspect pertaining to blood based medicine including but not limited to: Transfusion Medicine; Blood collection, Donor issues, Transmittable diseases, and Blood banking logistics; Immunohematology; Artificial and alternative

\section{Dovepress}

blood based therapeutics; Hematology; Biotechnology/nanotechnology of blood related medicine; Legal aspects of blood medicine; Historical perspectives. The manuscript management system is completely online and includes a very quick and fair peer-review system. Visit http://www.dovepress.com/ testimonials.php to read real quotes from published authors. 